\section{LESSON 136}

Letter 47

PAPER: A4.

TARGET TIME: 30 minutes.

Take one carbon copy and address a suitable envelope. If you have a headed sheet of paper, use it - if not centre this address: Hope \& Taylor Ltd., Heating Engineers, Raven Street, Rotherham. RO1 2SE.

This letter will require a continuation sheet.
Ref. DH/NQ To-day's date

To: M. Spears, Esq., 31 Peak Road, Doncaster. DO9 3NE Dear Sir, In recent months we.have been inundated with service calls because heating systems have been breaking down and in nearly all cases these were simply through lack of routine maintenance. Some of these have been rather expensive repairs, most of which would have been avoided through regular servicing. In reply to your recent letter we would, therefore, like to introduce you to our Maintenance Service Scheme and if you think it would help you, please get in touch with us again and we will send you a Maintenance Service Contract for signing. (Paragraph) Our Maintenance Service Department operates a 24 hour service and employs only qualified engineers, who work to a very high standard - covering plumbing, electrical repairs, gas, solid fuel, oil and warm air central heating. (Paragraph) Under our Maintenance Service Contract, our service engineer would carry out the following operations: 1 . Clean boiler flueways. 2 . clean inside firebox. 3. Remove soot from flues and firebox. 4. Check on refractors. 5. Check stabilizers and reset if necessary. 6. Remove and clean flue thermostat. 7. Lubricate the burner motor. 8. Check the fire valve and fusible link. 9. Check and report on fuel tank (oil systems only). 10. Leave the apparatus to be switched on at the client's request. ll. Check all controls, i.e., (i) Boiler thermostat. (ii) Burner control panel. (iii) Time clock and room thermostat. 12. Set the unit to operate at the most economical level and run for one hour before leaving the premises. (Paragraph) our price for carrying out this service is $£ 5.50$ a year. The engineer would undertake to visit you 3 times a year and to carry out the above work once a year on your instructions. If the engineer was called out other than his 3 annual service visits, a charge of $f l .50$ would be made for each visit. Any replacements which may be required would be chargeable to you and we would require your written confirmation before we would supply and fit them. (Paragraph) We hope that our proposals answer your questions and look forward to hearing should you decide that you would like to accept our Service Contract. One final point, however, we insist that if you decide to accept, you must do so on the understanding that we have 3 months' notice in writing in the event of cancellation. Yours faithfully, D. Hurst Service Manager

$$
\begin{aligned}
& \text { Typist. Please display the numbered items, leaving one blant } \\
& \text { line between each item. Type the section in roman numerals } \\
& \text { in single line Spacing. }
\end{aligned}
$$

LESSON 136 